\title{
Unusual epithelial-myoepithelial carcinoma in palate- case report and immunohistochemical study
}

\author{
Pollianna Muniz Alves ${ }^{1}$, Luiz Augusto Costa da Silva ${ }^{2}$, Gustavo Pina Godoy ${ }^{1}$, Daliana Queiroga de Castro \\ Gomes $^{1}$, Lélia Maria Maria Guedes Queiroz ${ }^{3}$, Hébel Cavalcanti Galvão ${ }^{3}$
}

\footnotetext{
${ }^{1}$ Professor, Department of Oral Pathology, School of Dentistry University of the State of Paraíba, Campina Grande-PB, Brazil. ${ }^{2}$ Student of Dentistry, Department of Oral Pathology, School of Dentistry, University of the State of Paraíba, Campina GrandePB, Brazil.

${ }^{3}$ Professor, Department of Oral Pathology, School of Dentistry, Federal University of Rio Grande do Norte, Natal- RN, Brazil..
}

Correspondence:

Pollianna Muniz Alves

Celestino Martins Costa street, 147, Catolé,

Campina Grande, PB, CEP: 58104-720, Brazil.

Email:polliannaalves@ig.com.br

Muniz Alves P, Costa da Silva LA, Pina Godoy G, Queiroga de Castro
Gomes D, Maria Guedes Queiroz L, Cavalcanti Galvão H. Unusual
epithelial-myoepithelial carcinoma in palate- case report
and immunohistochemical study. J Clin Exp Dent. 2010;2(1):e22-5.
http://www.medicinaoral.com/odo/volumenes/v2il/jcedv2ilp22.pdf

Article Number: 678923 http://www.medicinaoral.com/odo/indice.htm

(C) Medicina Oral S. L. C.I.F. B 96689336 - eISSN: 1989-5488

eMail: jced@jced.es

\begin{abstract}
Ephitelial-myoepithelial carcinoma (EMC) is a neoplasm of salivary gland extremely rare and low-grade malignant, exhibiting predilection for major salivary gland, especially parotid gland. This paper described a case of EMC localized in soft palate. The initial clinical diagnosis were mucoepidermoid and adenoid cystic carcinoma. A incisional biopsy was performed, and the histological diagnosis was adenocarcinoma not otherwise specified. The patient underwent excisional biopsy, where was realized immunohistochemical analysis, staining the duct-like structures, where the inner layer of epithelial cells positively for CK 14, whereas outer layer of myoepithelial cells stained positively for smooth muscle actin (SMA) and vimentin antibodies. Based on these findings, the final histological diagnosis was EMC. The patient was submitted 30 sessions of radiotherapy, and she is being follow-up about 2 years without evidence recurrences.
\end{abstract}

Key words: Ephitelial-myoepithelial carcinoma, oral cavity, soft palate, immunohistochemistry. 


\section{Introduction}

Epithelial-myoepithelial carcinoma (EMC) is defined by the World Health Organization (WHO) classification in 1991 as a rare low-grade malignant neoplasm and account for than $1 \%$ of salivary glands tumors $(1,2)$. Though the name for this tumor was coined by Donath et al. (1972), EMC was likely recognized as early as 1956 and reported under a variety of names such as adenomyoepithelioma, clear cell adenoma, tubular solid adenoma and clear cell carcinoma (3).

This tumor arising most frequently $(80 \%)$ in the parotid gland, but lesions have also been reported in submandibular glands $(10 \%)$ and minor salivary glands $(1 \%)(1,4)$. Histologically, it is characterized by variable proportions of duct-forming eosinophilic cells and myoepithelial differentiated clear cells surrounding duct-forming cells $(5,6)$. Immunohistochemical studies realized to show to be useful in separating EMC from similar tumors, as pleomorphic adenoma and adenoid cystic carcinoma, by highlighting the characteristic biphasic epithelial-myoepithelial phenotype $(7,8)$.

This paper reported a rare case of EMC localized in minor salivary glands, specifically in soft palate, as well as discuss the findings immunohistochemical, emphasizing the possibilities involved in the genesis of this neoplasm.

\section{Case Report}

A 76-year-old-women was referred to the Department of Dentistry of State University of Paraíba, in Brazil, for diagnosis and treatment of a lesion in soft palate. She had noticed the lesion for about 1 year and complaining of lesion that was "growing and difficult to breath". In extra-oral examination was not observed any alterations. In intra-oral examination showed fibrous tumoral lesion in soft palate, of regular surface, erythematous and asymptomatic (Fig. 1). The hypothesis initial clinical diagnosis were mucoepidermoid and adenoid cystic carcinoma. It was requested panoramic radiograph, in which there was no bone involvement. In incisional

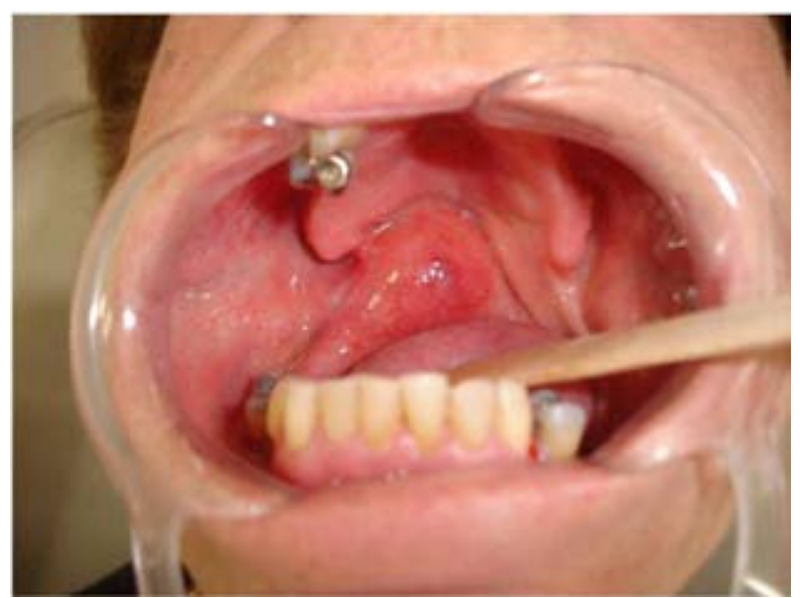

Fig.1. Tumoral erythematous lesion observed in soft palate region. biopsy the diagnosis histological was adenocarcinoma not otherwise specified. Computed tomography demonstrated a tumor occupying the left side palate. The patient underwent subsequent excisional biopsy. Microscopically, observed by hematoxylin-eosin staining the presence of double-layered duct-like structures with an inner layer of epithelial cells and outer layer of clear myoepithelial cells, forming solid nests and myxoid islets. The epithelial cells were small cuboidal to be oval, scarce in number, with a central hyperchromatic nucleus and scant eosinophilic cytoplasm. The myoepithelial cells were polygonal with more abundant, clear, vacuolated and well-defined cytoplasm, and an eccentric irregular nucleus. The fibrous connective tissue band contained numerous blood vessels and necrosis was found locally (Fig. 2).

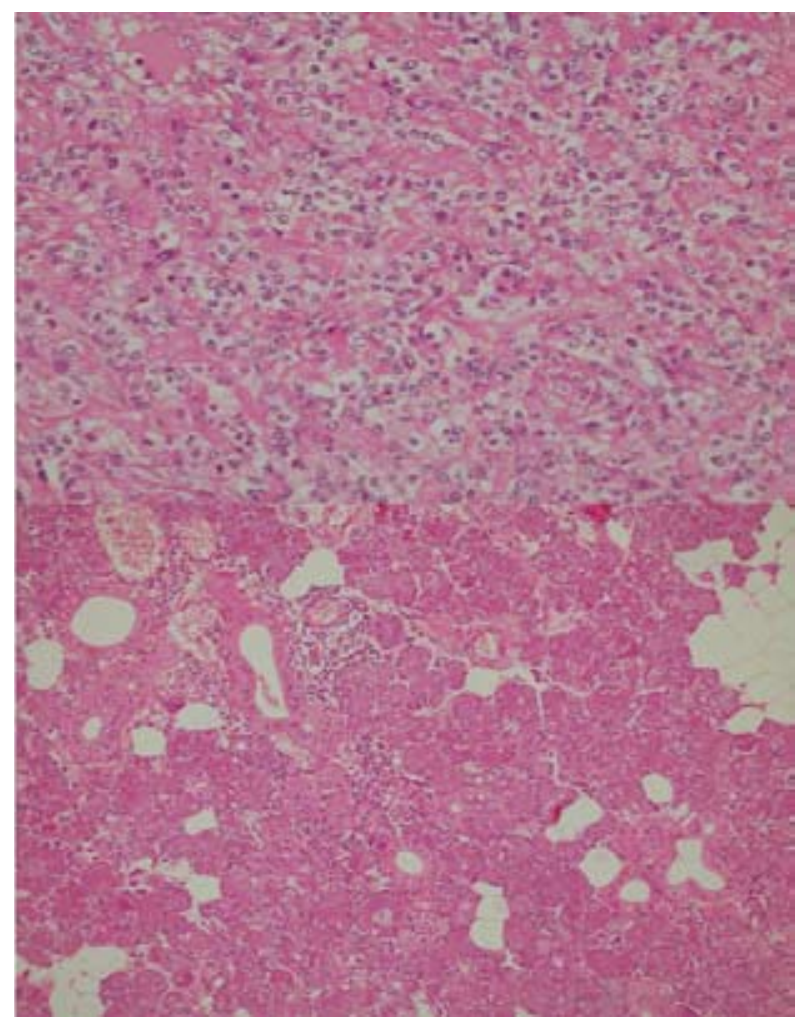

Fig.2. Histology of the tumor (H/E, 100X). Myoepithelial cells were polygonal with abundant clear cytoplasm arranged in sheets (A). Epithelial duct-forming cells were small cuboidal with a central nucleus and scant cytoplasm (B).

Immunohistochemical staining was carried out with the streptavidin-biotin method. Immunoreactivity for CK7 and CK14 was observed in inner layer of epithelial cells, as well as in mucous acinus and duct salivary. The clear cells of outer layer were found to stain positively for smooth muscle actin (SMA), which is consistent with a myoepithelial phenotype. In solid areas observed immunoreactivity for vimentin in muscle cells around blood vessels and small clear cells nests, confirming the myoepithelial characteristic (Fig. 3). 


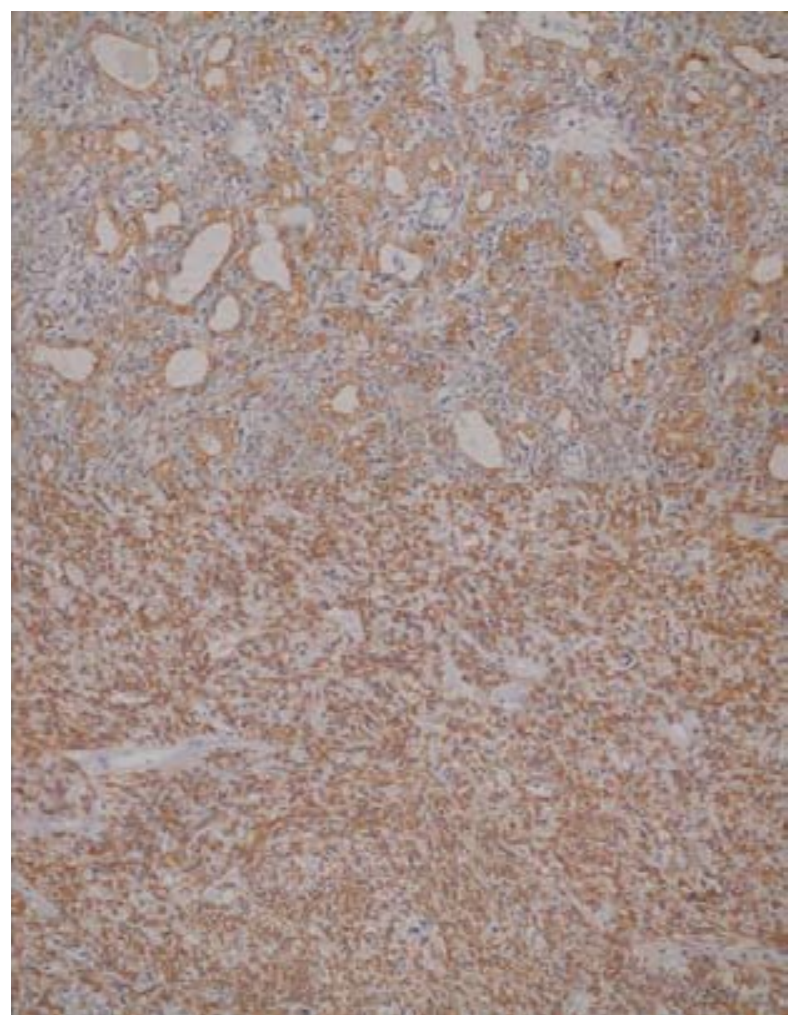

Fig.3. Immunohistochemical staining of the tumor (200X). Ductforming epithelial cells positive for CK14 (A) and myoepithelial clear cells positive for SMA (B).

Based on these findings, the final histological diagnosis was EMC. The patient was submitted 30 sessions of radiotherapy, and she is being follow-up about 2 years without evidence neither recurrences and metastasis.

\section{Discussion}

Epithelial-myoepithelial carcinoma, recognized by WHO in 1991, is a rare malignant neoplasm in the salivary glands, comprising approximately $1 \%$ of all salivary gland tumors (9). The case related was localized in the soft palate, a rare area of onset, where it showed histologic characteristics of a low-grade behavior of aggressiveness. Rarely, high-grade or dedifferentiated EMC has been described $(10,11)$.

These tumors arise in the salivary glands, predominantly the major salivary gland and the parotid gland (6). However, they have rarely been observed in tissues other than the salivary glands, such as the breast, lacrimal gland, lung and nasal cavity $(6,12,13)$.

It is more frequent in elderly women, especially in the seventh decade (1). Approximately $60 \%$ of patients with EMC are female (2). The patient here was 72 years-old female, such as in the mean age reported in the literature. She is being follow-up about 2 years, without any evidence recurrences. In the series reported by Seethala et al. (3), the recurrence rate was $36,3 \%$ in the 11 -year disease-free survival, but death was rare with 5 -year
$(93,5 \%)$ and 10 -year $(81,8 \%)$ disease-specific survivals. However, Fonseca and Soares (14) reported that the 5 -year survival rate was $6 \%$ and $40 \%$ of patients died of their disease. In these cases, the authors suggest that the classification of epithelial-myoepithelial carcinoma as low-grade should be reviewed, as the clinical behavior of the tumor contrasts with its histopathologically bland appearance.

EMC has been postulated to be derived from the intercalated ducts of salivary glands, because the tubular growth pattern of this tumor recapitulates this phenotype. More current concepts of salivary gland tumorigenesis avoid attributing tumors to a specific structure or cell type of origin, focusing instead on classification based on the morphologic and immunophenotypic differentiation (3). Studies have reported that pleomorphic adenoma cell culture are monoclonal, probably deriving from a common precursor of myoepithelial and ductal cells. In contrast, epithelial-myoepithelial carcinoma cell culture present two different cell populations, already committed to luminal and myoepithelial differentiation (15). Although the histological appearance of the EMC is usually characteristic, immunohistochemical studies may prove to be useful in separating of others similar tumors, as adenoid cystic and pleomorphic adenoma (8).

In the present case, the tumor was composed of two types of cells, one type of duct-forming cell and other type of cells surrounding these cells. However, the pattern of the cellular arrangement found in this tumor excludes the possibility of an adenoid cystic carcinoma. The tumour also exhibiting greater epithelial cellularity with less stroma compared to pleomorphic adenomas. Immunohistochemically, in this case was observed that the myoepithelial cells were positive for vimentin and smooth muscle actin (SMA) and the epithelial cells were positive for CK 7 and CK 14. Seethala et al. (3) also observed that vimentin and SMA were positive in $75 \%$ and $81,8 \%$ for myoepithelial cells, respectively. According to this author, among of the myoepithelial markers, p63 has the best performance, showing diffuse strong staining in large number of cases, with no staining of epithelial cells.

In some cases, adenoid cystic carcinoma (ACC) can also show a double-layered, duct-like structure, it can be mistaken for ECM. But, the inner ductal cell layer in ACC stain positive for the S-100 protein, whereas only the outer ductal cell layer in ECM is positive for the S-100 protein. The different immunostaining characteristics will be useful for distinguishing between EMC and ACC when necessary (2).

Furuse et al. (5) observed nuclear staining of myoepithelial cells for $\beta$-catenin protein in 10 cases of ECM, suggesting that it may be related aggressive biologic behavior of the tumor. According these authors, the universal expression of E-cadherin and $\beta$-catenin in salivary gland 
tumors may explain the slow growth and later metastasis seen in these tumors compared with other carcinomas, which confirms the role of both E-cadherin and $\beta$-catenin as tumor-suppressing and invasion-suppressing molecules. In the case of ECM, when myoepithelial cells participate in tumor pathogenesis, the expression of E-cadherin/ $\beta$-catenin complex should be considered a useful prognostic marker.

Actually, there is no consensus regarding the optimal treatment of ECM. In our case, surgical excision was done with the margin all around the tumor. No recurrences or metastasis were found 24 months after the surgery. The adjunctive radiation therapy is sometimes used, and in this case, the patient was submitted 30 sessions of radiotherapy, of 100 grays each, and she is making prosthodontic rehabilitation.

\section{References}

1. Mantesso A, Loducca SV, Jaeger RG, Décio SP, Araújo VC. Analysis of epithelial-myoepithelial carcinoma based on the establishment of a novel cell line. Oral Oncol. 2003;39:453-8.

2. Kumai Y, Ogata N, Yumoto E. Epithelial-myoepithelial carcinoma in the base of the tongue: a case report. Am J Otolaryngol. 2006;27:5860.

3. Seethala RR, Barnes EL, Hunt JL. Epithelial-myoepithelial carcinoma: a review of the clinicopathologic spectrum and immunophenotypic characteristics in 61 tumors of the salivary glands and upper aerodigestive tract. Am J Surg Pathol. 2007;31:44-57. Erratum in: Am J Surg Pathol. 2008;32:1923.

4. Yamada H, Kawaguchi K, Yagi M, Morita Y, Mishima K, Uno K, et al. Epithelial-myoepithelial carcinoma of the submandibular gland with a high uptake of $18 \mathrm{~F}-\mathrm{FDG}$ : a case report and image diagnosis. Oral Surg Oral Med Oral Pathol Oral Radiol Endod. 2007;104:243-8.

5. Furuse C, Cury PR, Altemani A, dos Santos Pinto D Jr, de Araújo NS, de Araújo VC. Beta-catenin and E-cadherin expression in salivary gland tumors. Int J Surg Pathol. 2006;14:212-7.

6. Yamanegi K, Uwa N, Hirokawa M, Ohyama H, Hata M, Yamada N, et al. Epithelial-myoepithelial carcinoma arising in the nasal cavity. Auris Nasus Larynx. 2008;35:408-13.

7. de Araújo VC, de Sousa SO, Carvalho YR, de Araújo NS. Application of immunohistochemistry to the diagnosis of salivary gland tumors. Appl Immunohistochem Mol Morphol. 2000;8:195-202.

8. Furuse C, Sousa SO, Nunes FD, Magalhães MH, Araújo VC. Myoepithelial cell markers in salivary gland neoplasms. Int J Surg Pathol. 2005;13:57-65.

9. Kusafuka K, Takizawa Y, Ueno T, Ishiki H, Asano R, Kamijo T, et al. Dedifferentiated epithelial-myoepithelial carcinoma of the parotid gland: a rare case report of immunohistochemical analysis and review of the literature. Oral Surg Oral Med Oral Pathol Oral Radiol Endod. 2008;106:85-91.

10. Daa T, Kashima K, Gamachi A, Nakayama I, Yokoyama S. Epithelial-myoepithelial carcinoma harboring p53 mutation. APMIS. 2001;109:316-20.

11. Fonseca I, Félix A, Soares J. Dedifferentiation in salivary gland carcinomas. Am J Surg Pathol. 2000;24:469-71.

12. Ostrowski ML, Font RL, Halpern J, Nicolitz E, Barnes R. Clear cell epithelial-myoepithelial carcinoma arising in pleomorphic adenoma of the lacrimal gland. Ophthalmology. 1994;101:925-30.

13. Wilson RW, Moran CA. Epithelial-myoepithelial carcinoma of the lung: immunohistochemical and ultrastructural observations and review of the literature. Hum Pathol. 1997;28:631-5.

14. Fonseca I, Soares J. Proliferating cell nuclear antigen immunohistochemistry in epithelial-myoepithelial carcinoma of the salivary glands. Arch Pathol Lab Med. 1993;117:993-5.

15. Watt FM, Hogan BL. Out of Eden: stem cells and their niches.
Science. 2000;287:1427-30. 